\title{
Comparing the efficiency of flowsheets for hot die forging on crank presses
}

\author{
Igor Telegin ${ }^{1, *}$, and Tatyana Shumilova ${ }^{1}$ \\ ${ }^{1}$ Lipetsk State Technical University, Lipetsk, Russia
}

\begin{abstract}
The process of manufacturing a part as a semi-finished product (a forging) using hot die forging with further machining can be performed on various types of press forging equipment following several flowsheet variants. The task of selecting the best (most effective) variant is not always obvious. The paper considers the methods of the comparative estimation of the efficiency of several variants of manufacturing a forging of the same part on the basis of the following groups of indicators: metal consumption and forging force.
\end{abstract}

\section{Research objective}

Hot die forging on crank hot-forging presses is among the most common techniques of manufacturing semi-finished products from which finished parts used in engineering are obtained after machining [1]. As a rule, the process of manufacturing a forging of the desired configuration includes several impressions the geometry of which is defined as a flowsheet. The same forging can be manufactured on the basis of various flowsheets [2]. The present paper considers the methods for determining the best variant of the hot die forging flowsheet for crank hot-forging presses from several possible variants.

\section{Calculating the efficiency of hot-forging flowsheet variants}

The effectiveness of any system is quantified on the basis of calculating its indicators [3]. This paper considers:

1. Metal consumption of the process $[4,5]$,

2. Technological forging force $[2,6]$

to be the main groups of efficiency indicators of the flowsheet for manufacturing a forging by the hot die forging method on crank hot-forging presses.

\subsection{Metal consumption of the hot die forging process on crank hot-forging presses}

The metal consumption of the process of manufacturing a part will be estimated using the metal utilization factors $K_{U}$ and ${ }_{\min } K_{U}(1)$ and the forging accuracy factor $K_{F}(2)$ :

\footnotetext{
${ }^{*}$ Corresponding author: igor.v.telegin@gmail.ru
} 


$$
K_{U}=\frac{\not{ }^{M}}{0.5 \cdot\left({ }_{3} M_{\min }+{ }_{3} M_{\max }\right)} \leq 1,{ }_{\min } K_{U}=\frac{д^{M}}{{ }_{3} M_{\max }} \leq 1,
$$

where ${ }_{W} M_{\min },{ }_{W} M_{\max }$ are minimum and maximum masses of the workpiece; ${ }_{P} M$ is the mass of the part.

It is obvious that the higher $K_{U}$ and ${ }_{\min } K_{U}$, the more effective the technological process is.

The minimum and maximum masses of the workpiece depend on many factors including:

- accuracy of rolled products, the method of cutting and heating the workpiece $[4,5]$;

- the forging flowsheet [6-8];

- allowances, tolerances and forge surpluses [2].

The minimum mass of the workpiece is equal to the minimum mass of the forging plus metal losses caused by heating. Its value can be determined by numerical simulation, e.g., in the QFORM program, or experimentally. This happens because the die impression cavities, especially when forming the external radii of the forging, are often finally filled simultaneously with the extrusion of metal with flash formation (or into the compensator) (Fig. 1) with a sharp increase in the forging force.

The maximum mass ${ }_{W} M_{\max }$ of the workpiece is greater than the minimum one due to the inaccuracy of rolled products, metal losses due to its cutting and heating $[4,5]$.

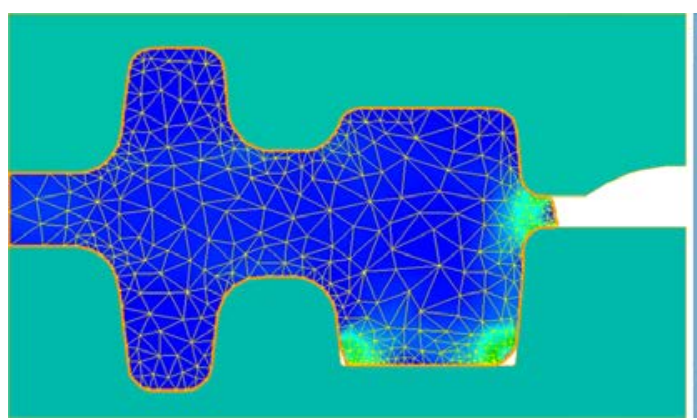

$a$

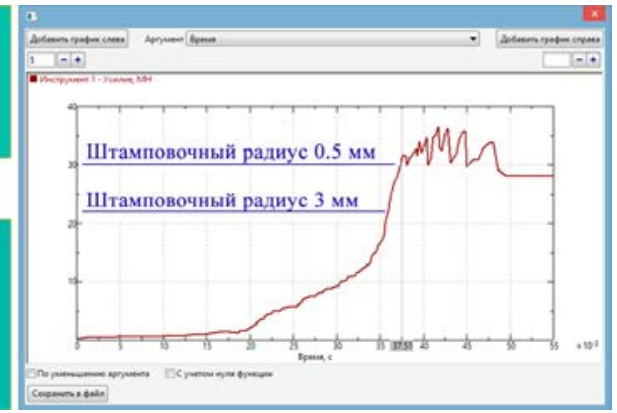

$b$

Fig. 1. Forging the "Pinion" part on the final impression: a - the final impression (forming the forging radii), $\mathrm{b}$ - the technological forging force.

The forging accuracy factor $K_{F}$ :

$$
K_{\Pi}=K_{\Pi}=\frac{д^{M}}{{ }_{\Pi} M} \leq 1,
$$

where ${ }_{F} M$ are masses of the forgings. The mass of the forging depends on the hot die forging flowsheet, is determined by the shape of the part, allowances, tolerances and surpluses specified for its dimensions. Quite time-consuming calculations of the volumes of round forgings and analyses of the obtained results are automated.

\subsection{Technological forging force}

Reasonable values of this indicator can be obtained by applying programs for modeling the hot die forging process by the finite element method. In this paper, QFORM (QuantorForm Ltd., Russia) was used for this purpose. 
Technological force, as well as metal consumption, is the most important criterion for the technological process efficiency. In order to quantitatively evaluate the technological force, its maximum $P_{\max }$ value will be used, as well as the values of the minimum and the average safety factors $K_{S},{ }_{a v} K_{S}$ on crank hot-forging presses when performing the technological operation (3).

$$
K_{3 C}=\min \left(\frac{P_{\partial n}(\varphi)}{P_{\text {mex }}(\varphi)}\right)>1, \quad{ }_{c p} K_{3 C}=\frac{\int_{\varphi_{1}}^{\varphi_{2}} P_{\partial n}(\varphi) d \varphi}{\int_{\varphi_{1}} P_{\text {mex }}(\varphi) d \varphi}>1,
$$

where $P_{a s}(\varphi), P_{\text {tech }}(\varphi)$ are the functions of changes in allowable stresses on the press slide and in the technological force depending on the rotation angle of the crank press main shaft in the interval $[\varphi 1, \varphi 2]$.

The efficiency factor ${ }_{a v} K_{S}$ is the ratio of the areas under the graphs of the allowable forces on the slide and the technological force. Physically, it is the ratio of the maximum possible work of the press to the work of plastic deformation forces.

\section{Estimating the efficiency of flowsheet variants in forging the "Synchronizer hub" part}

Fig. 2 shows the "Synchronizer hub" part of the KAMAZ vehicle (further referred to as the pinion) and the technological impressions of hot die forging on crank hot-forging presses used in the manufacture of its forging in accordance with the traditional flowsheet. The mass of the part is $5.272 \mathrm{~kg}$. The mass of the forging without surplus and losses caused by the workpiece manufacture is $6.5 \mathrm{~kg}$.

The main features of the methods for calculating the hot die forging efficiency indicators on crank hot-forging presses used for manufacturing round forgings are considered on the example of improving this flowsheet (Fig. 2).

When manufacturing the forging of the pinion in accordance with the traditional flowsheet, the forged semi-finished product is formed in the open die of the preliminary impression from the workpiece obtained by setting (Fig. 2b, c). Before the final impression, the flash is cut in the closed die, then the final forging is performed and the connector is punched (Fig. 2d, d). Forging is performed on the crank hot-forging press K8544 with a nominal force of $25 \mathrm{MH}$.

The minimum height of the workpiece with nominal diameter of $90 \mathrm{~mm}$ (round steel according to GOST 2590-2005, accuracy B1) calculated by modeling the hot die forging process on crank hot-forging presses in the QFORM program is $140.5 \mathrm{~mm}$. The maximum height of the workpiece is $150.76 \mathrm{~mm}$. The average mass of the workpiece is $7.4 \mathrm{~kg}$. 


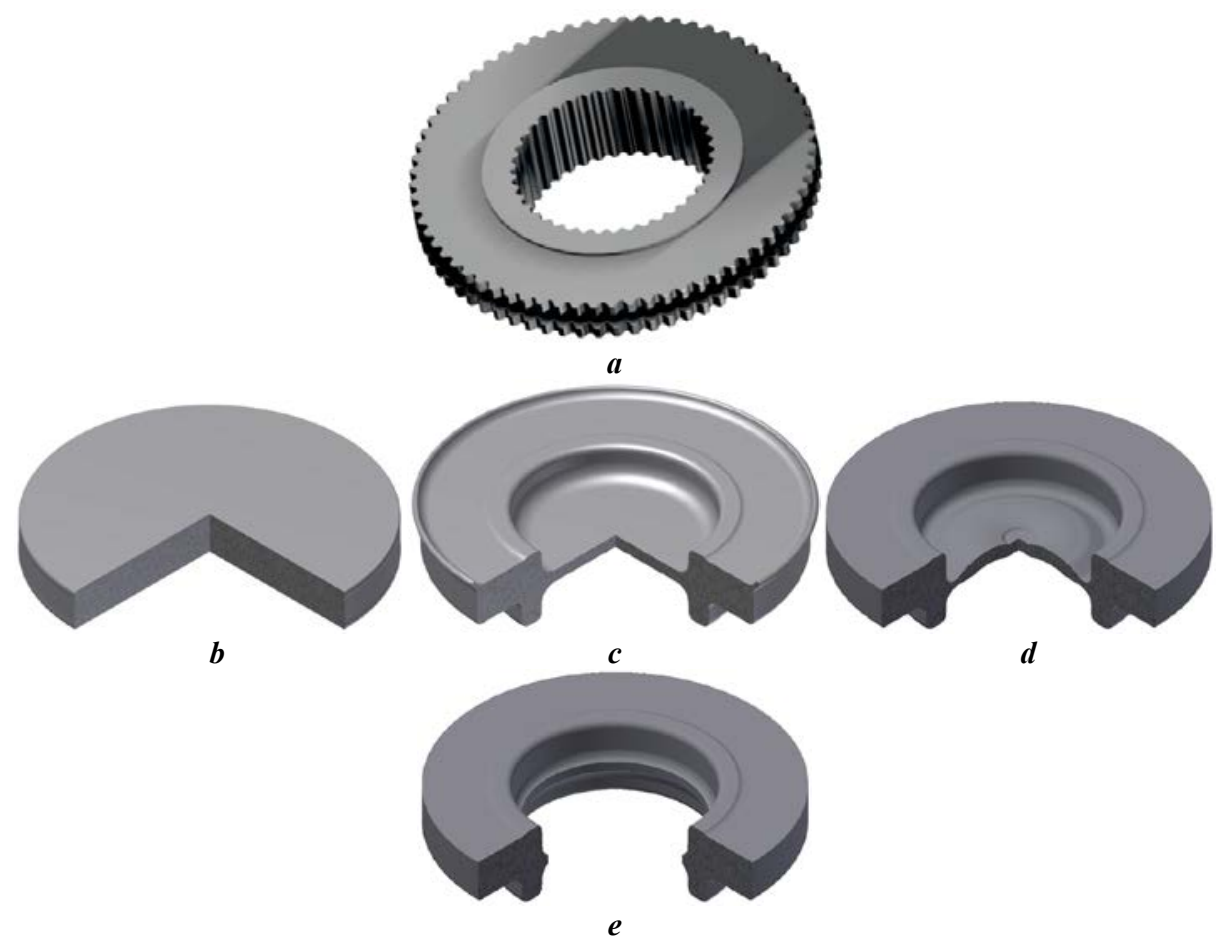

Fig. 2. The "pinion" part and forging impressions of the hot die forging process on crank hot-forging presses to manufacture its forging in accordance with the traditional technology: $\mathrm{a}-$ pinion part, $\mathrm{b}-$ setting, $\mathrm{c}$ - preliminary forging, $\mathrm{d}$ - flash cutting and final forging, $\mathrm{e}$ - punching the connector.

Variant 1. Modeling the hot die forging process of the "pinion" part on the crank hotforging press K8544 in accordance with the traditional flowsheet is shown in Fig. 3.

The calculated values of performance indicators are: $K_{U}=0.726\left({ }_{\min } K_{U}=0.704\right) ; K_{F}=$ 0.784; $P_{\max }=23.37 \mathrm{MH} ; K_{S}=1.07\left({ }_{a v} K_{S}=15.4\right)$.
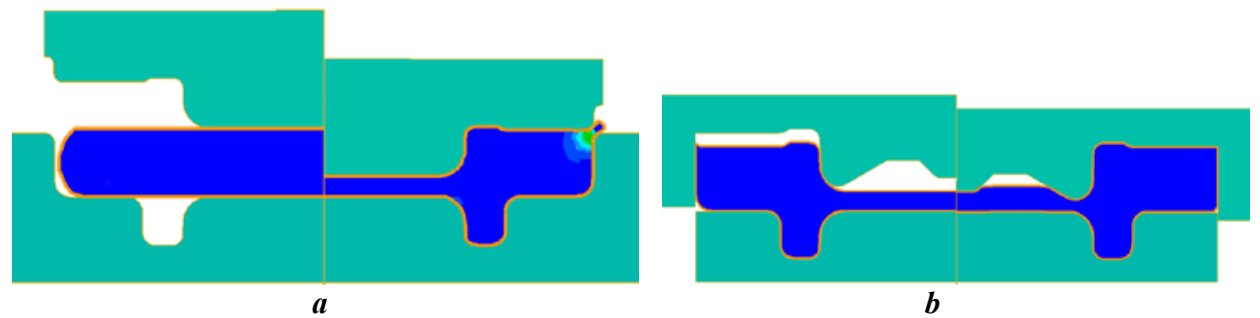

Fig. 3. The "pinion" part. The traditional hot die forging flowsheet (Variant 1): a preliminary impression, $\mathrm{b}$ - final impression.

Variant 2. This particular flowsheet can be improved [2] by forming a projection in the preliminary impression (Fig. 4). The result is the formation of an outer radius of curvature with a value of $\approx \mathrm{R} 0.5 \mathrm{~mm}$, hence a reduction of the forging mass due to lower allowances for machining, as well as a lower technological effort in the final impression.

The calculated values of performance indicators are: $K_{U}=0.738\left({ }_{\min } K_{U}=0.717\right) ; K_{F}=$ 0.858; $P_{\max }=18.6 \mathrm{MH} ; K_{S}=1.29\left({ }_{a v} K_{S}=5.32\right)$. 


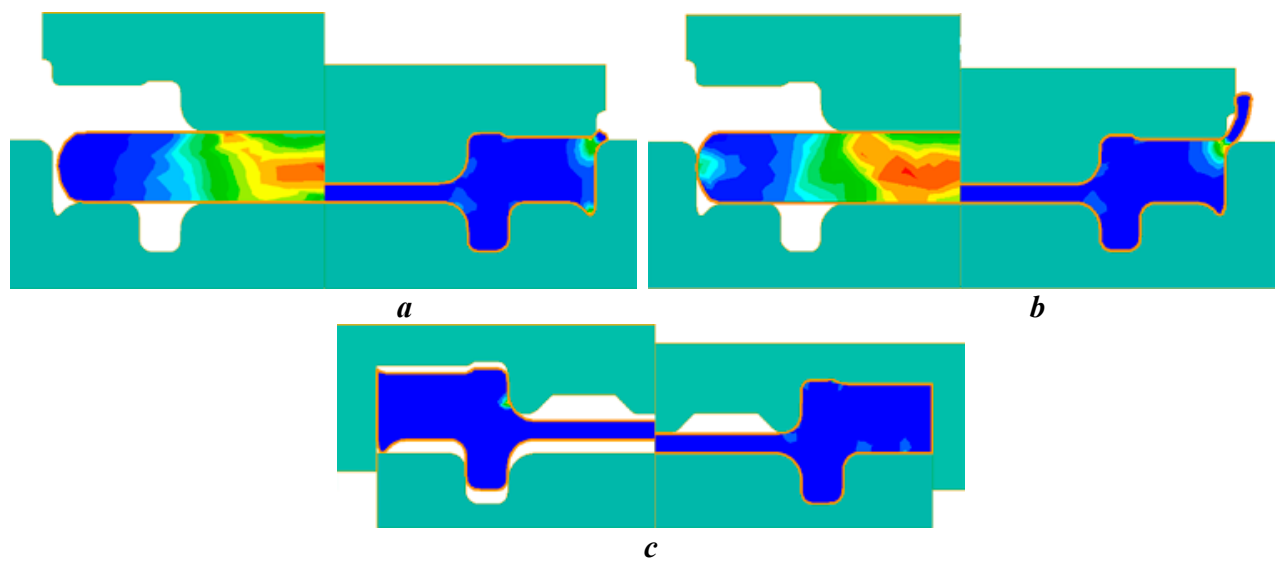

Fig. 4. The "pinion" part. The advanced hot die forging flowsheet (Variant 2): a, b - preliminary impression at minimum and maximum workpiece masses, $\mathrm{c}$ - final impression

Variant 3. Fig. 5 shows the third version of the hot die forging flowsheet. Punching on the preliminary impression is closed. The two projections formed in this impression are simultaneously compensators for metal surpluses. The final impression is open.

The calculated values of performance indicators are: $K_{U}=0.749\left({ }_{\min } K_{U}=0.727\right) ; K_{F}=$ $0.858 ; P_{\max }=11.81 \mathrm{MH} ; K_{S}=1.21\left({ }_{a v} K_{S}=7.74\right)$.

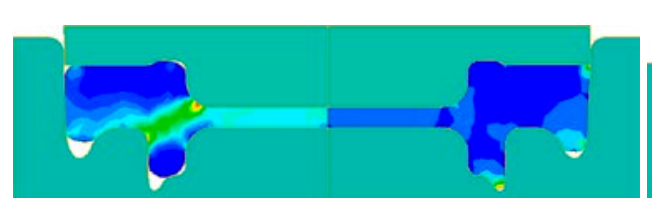

$\boldsymbol{a}$

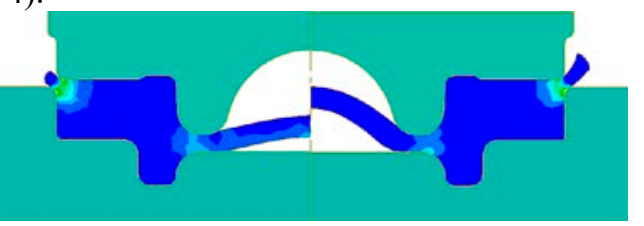

$b$

Fig. 5. The "pinion" part. detail of the gear. The advanced hot die forging flowsheet (Variant 3): a preliminary impression at minimum and maximum workpiece masses, $b$ - final impression at minimum and maximum workpiece masses.

\section{Summary}

A comparative evaluation of the three flowsheet variants for forging the "pinion" part showed that the best metal consumption indicators are typical for variant No. 3 . This is due to the possibility of lowering the allowances for machining by forming special projections on the preliminary impression, the deformation of which serves as the beginning of forming the outer curvature radii of the forging in the impression (Fig. 4c). Besides, there is no extra metal consumption to form the flash as an obligatory condition for filling the inner corners of the die impression. In addition, the application of open forging in the final impression and no need to displace the metal as flash in forming the projections in the preliminary impression made it possible to reduce technological forces both in the preliminary and final impressions.

An essential advantage of the third variant of the die forging flowsheet is the possibility of applying crank hot-forging presses with a capacity of $16 \mathrm{MN}$ instead of $25 \mathrm{MN}$ to perform hot die forging operations. However, the application of a cheaper press (the cost of the crank hot-forging press is roughly proportional to its capacity) which operates at its maximum $\left({ }_{\min } K_{3} \rightarrow 1\right)$ requires additional studies [6,9-12] related to the analysis of the influence of dynamic processes in the crank hot-forging press on its function. 
The results were obtained within of the state assignment of the Ministry of Education and Science of Russia (project No. 11.9505.2017/8.9).

\section{References}

1. I.M. Volodin, A.A. Romashov, The system of basic principles of designing hot die forging processes and technologies developed on its basis, Forging production. Metal forming, No. 9, pp. 19-29 (2008)

2. Telegin, I.V., Volodin, I.M., Zolotukhin, P.I. The mathematical modeling for assessing the effectiveness of hot forging extruded round in plan forgings on crank presses, International Journal of Engineering and Technology (UAE), pp. 30-34 (2018)

3. Antonov, AV, Systems Analysis, Textbook for Higher Educational Institutions, Moscow, Vysshaya shkola, (2004)

4. I.V. Telegin, A study of metal fabrication blanks from long products, BEST: International Journal of Management, Information Technology and Engineering, Vol. 4-11. pp. 1-6 (2016)

5. E.I. Semenov, Forging and hot die forging, Textbook, Moscow, MSIU, 414 p. (2011)

6. I.M. Volodin, I.V. Telegin, Study of influence of geometric parameters tool for hot volume stamping of orbicular in terms of forging on crank press dynamics, Global Journal of Engineering Science and Researches, v. 4(1). pp. 57-61 (2017).

7. I.M. Volodin, Simulation of hot die forging: Monograph - M .: Mechanical Engineering - 1, 253 p (2006)

8. E.I. Semenov, Forging and die forging, Directory, Mechanical engineering, Vol. 1, 720 p. (2010)

9. V.V. Telegin, A.M. Kozlov, V.I. Sakalo, Solid Modeling and Dynamic Analysis of Mechanisms of Press-forging Machines, Procedia Engineering, v. 206, pp. 1258-1263 (2017).

10. V. Telegin, A. Kozlov, Computer rea-lization of research into the dynamics of mechanical systems, IOP Conference Series: Materials Science and Engineering, v. 124, pp. 012101 (2016).

11. I. Telegin, A. Kozlov, A. Zhirkov, Component simulation in problems of calculated model formation of automatic machine mechanisms, MATEC Web Conf. International Conference on Modern Trends in Manufacturing Technologies and Equipment (ICMTMTE 2017), v. 129, 03016 (2017).

12. Zolotukhin, P.I., Volodin, I.M., Karpaitis, E.P., Volodin, A.I., Schmidt, A.A. Study of the spring back of calibres in material forming processes of roll forging mills, Ironmaking and Steelmaking, pp. 1-5 (2017) 